\title{
Expression of Glioma-associated oncogene homolog 1 as biomarker with sonidegib in advanced basal cell carcinoma
}

\author{
Reinhard Dummer ${ }^{1}$, Li Liu², Nicholas Squittieri², Ralf Gutzmer ${ }^{3}$ and John Lear ${ }^{4}$ \\ ${ }^{1}$ Department of Dermatology, University of Zürich, Skin Cancer Center, University Hospital, Zürich, Switzerland \\ ${ }^{2}$ Sun Pharmaceutical Industries, Inc., Princeton, NJ, USA \\ ${ }^{3}$ Skin Cancer Center Hannover, Department of Dermatology, Hannover Medical School, Hannover, Germany \\ ${ }^{4}$ Manchester Academic Health Science Centre, Manchester University and Salford Royal NHS Trust, Manchester, UK \\ Correspondence to: Reinhard Dummer, email: reinhard.dummer@usz.ch
}

Keywords: biomarker; Glioma-associated oncogene homolog 1; basal cell carcinoma; Hedgehog pathway inhibitor; sonidegib Received: May 27, $2020 \quad$ Accepted: August 17, $2020 \quad$ Published: September 15, 2020

Copyright: ( 2020 Dummer et al. This is an open access article distributed under the terms of the Creative Commons Attribution License (CC BY 3.0), which permits unrestricted use, distribution, and reproduction in any medium, provided the original author and source are credited.

\section{ABSTRACT}

The pivotal BOLT (Basal cell carcinoma Outcomes with LDE225 [sonidegib] Treatment) study established the durable efficacy and manageable toxicity of sonidegib $200 \mathrm{mg}$ once daily (QD) through $\mathbf{4 2}$ months in patients with advanced basal cell carcinoma (BCC). This secondary analysis used expression of Glioma-associated oncogene homolog 1 (GLI1) as a biomarker to assess the extent of Hedgehog pathway inhibition by sonidegib in patients with locally advanced BCC (IaBCC) and metastatic $B C C(\mathrm{mBCC})$. The study enrolled 230 patients, 79 and 151 receiving sonidegib 200 and $800 \mathrm{mg}$ QD, respectively. At week 17, GLI1 expression was reduced from baseline by a median percentage (95\% confidence interval) of $88.7 \%(54.6 \%-93.0 \%)$ and $97.0 \%$ (77.5\%-98.9\%) for aggressive laBCC, $97.5 \%(80.3 \%-98.8 \%)$ and $95.0 \%(80.7 \%-$ $97.5 \%)$ for nonaggressive laBCC, and $99.1 \%(96.4 \%-99.6 \%)$ and $99.3 \%(95.9 \%-$ $\mathbf{9 9 . 9 \% )}$ ) for $\mathrm{mBCC}$ in the 200 and $800 \mathrm{mg}$ groups, respectively. Substantial repression of GLI1 was observed in patient subgroups stratified by age, sex, BCC cytological subtype, Eastern Cooperative Oncology Group performance status, lesion site, baseline number of BCCs, and prior radiotherapy. Results support further studies on the inhibition of Hedgehog pathway genes by sonidegib in patients with laBCC and $\mathrm{mBCC}$.

\section{INTRODUCTION}

Basal cell carcinoma (BCC) is the most common skin malignancy, affecting more than 10 million new patients annually worldwide and with an incidence that increases by approximately $1 \%$ each year [1-3]. Most $\mathrm{BCC}$ are treated with surgery, with a favorable prognosis [4]. In cases of locally advanced BCC (laBCC) where surgery is contraindicated, inhibition of the Hedgehog pathway is one of the few approved and recommended treatment options $[4,5]$.

Most BCCs exhibit constitutive activation of the Hedgehog pathway due to mutations in pathway members, most often Patched 1 (PTCH1) and Smoothened (SMO) [6-8]. Expression of the transcription factor Gliomaassociated oncogene homolog 1 (GLII) is a biomarker for Hedgehog pathway activation [9].
Sonidegib, a Hedgehog pathway inhibitor (HHI), blocks pathway signaling by selective inhibition of $S M O$ [10]. It is approved in the US, EU, Switzerland, and Australia for the treatment of adult patients with laBCC not amenable to curative surgery or radiotherapy [11-14]. In Switzerland and Australia, sonidegib is also approved for the treatment of metastatic BCC (mBCC) $[13,14]$.

The efficacy and safety of 2 doses of sonidegib (200 and $800 \mathrm{mg}$ once daily [QD]) were assessed through 42 months of treatment in patients with advanced $\mathrm{BCC}$ in the Basal cell carcinoma Outcomes with LDE225 (sonidegib) Treatment (BOLT) study (NCT01327053) [15-18]. The primary analysis at 6 months showed objective response rate (ORR) $(95 \%$ confidence interval [CI]) of $43 \%(28 \%-$ $59 \%)$ and $38 \%(28 \%-48 \%)$ in $1 \mathrm{aBCC}$ and $15 \%(2 \%-45 \%)$ and $17 \%(5 \%-39 \%)$ in $\mathrm{mBCC}$ for the 200 and $800 \mathrm{mg}$ QD doses, respectively [18]. The final analysis at 42 months 
was the longest clinical trial follow-up to date with an HHI and reported ORR (95\% CI) of 56\% (43\%-68\%) and $46 \%(37 \%-55 \%)$ in $\mathrm{laBCC}$ and $8 \%(<1 \%-36 \%)$ and $17 \%(5 \%-39 \%)$ in $\mathrm{mBCC}$ for 200 and $800 \mathrm{mg} \mathrm{QD}$, respectively [15]. At 42 months, adverse events (AEs) with the approved $200 \mathrm{mg}$ QD dose were mostly Grade 1 or 2, manageable, and reversible with dose interruptions [15]. While some results regarding GLI1 expression associations with clinical outcomes were reported in the BOLT primary analysis [18], here we report the complete secondary biomarker analysis of Hedgehog pathway inhibition with sonidegib from the BOLT study.

\section{RESULTS}

\section{Patient disposition, demographics, and clinical characteristics}

Overall, 230 patients were enrolled in the study, of whom 79 and 151 were randomized to sonidegib 200 and $800 \mathrm{mg}$ QD, respectively (Supplementary Figure 1). At the time of data cutoff for biomarker analysis (6 months), 39 (49.4\%) patients in the $200 \mathrm{mg}$ group and 46 $(30.5 \%)$ patients in the $800 \mathrm{mg}$ group were still receiving treatment. The biomarker population included 67 and 83 patients randomized to sonidegib 200 and $800 \mathrm{mg}$ QD, respectively. AEs were the most common reason for discontinuation, reported for $16(20.3 \%)$ and $48(31.8 \%)$ discontinuing patients in the 200 and $800 \mathrm{mg}$ group, respectively.

Patient demographics and clinical characteristics were similar between the biomarker and intent-totreat (ITT) populations (Supplementary Table 1). The biomarker population was $62.7 \%$ and $65.1 \%$ male with mean (standard deviation [SD]) age of 65.6 (15.6) and 64.0 (14.9) years for the 200 and $800 \mathrm{mg}$ groups, respectively. The ITT population was $60.8 \%$ and $63.6 \%$ male with mean (SD) age of 65.6 (15.7) and 63.6 (14.6) years for the 200 and $800 \mathrm{mg}$ groups, respectively. Patients with laBCC comprised $91.0 \%$ and $91.6 \%$ of the biomarker population, and $83.5 \%$ and $84.8 \%$ of the ITT population for the 200 and $800 \mathrm{mg}$ groups, respectively.

\section{Reduction of GLI1 expression levels}

Median (95\% CI) GLI1 expression at baseline was $-2.64(-3.22,-2.27)$ and $-3.04(-3.21,-2.56)$ for 200 and $800 \mathrm{mg}$ groups, respectively. Longitudinal analyses showed substantial reductions in GLII expression from baseline. Expression was reduced by a median $(95 \% \mathrm{CI})$ of $87.4 \%(77.0 \%-96.1 \%)$ and $96.2 \%(94.1 \%-98.4 \%)$ at week 9, 92.7\% (78.4\%-96.8\%) and 95.8\% (91.8\%-98.2\%) at week 17, and 93.0\% (33.1\%-97.6\%) and 97.1\% (87.8\%$99.5 \%$ ) at the end of treatment (EOT) for the 200 and 800 mg groups, respectively (Supplementary Figure 2).
When patients in the 2 dose groups were stratified by the type of $\mathrm{BCC}$, median $(95 \% \mathrm{CI})$ reduction in GLI1 expression at week 9 was $87.4 \%$ (55.6\%-96.9\%) and $94.2 \%(87.8 \%-98.4 \%)$ for patients with aggressive laBCC, 86.7\% (80.8\%-96.1\%) and 97.2\% (95.0\%$98.9 \%$ ) for patients with nonaggressive laBCC, and $98.2 \%(85.1 \%-98.5 \%)$ and $99.2 \%(94.3 \%-99.6 \%)$ for patients with $\mathrm{mBCC}$ receiving sonidegib 200 and 800 mg QD, respectively (Figure 1). At week 17, median (95\% CI) percent reduction was 88.7\% (54.6\%-93.0\%) and $97.0 \%(77.5 \%-98.9 \%)$ for aggressive laBCC, $97.5 \%(80.3 \%-98.8 \%)$ and $95.0 \%(80.7 \%-97.5 \%)$ for nonaggressive laBCC, and 99.1\% (96.4\%-99.6\%) and $99.3 \%(95.9 \%-99.9 \%)$ for $\mathrm{mBCC}$ in the 200 and $800 \mathrm{mg}$ groups, respectively. Median $(95 \% \mathrm{CI})$ reduction in $G L I 1$ expression at EOT was $96.0 \%(67.9 \%-98.9 \%)$ and $98.0 \%$ $(90.6 \%-99.7 \%)$ for patients with aggressive laBCC, $73.0 \%$ (49.5\%-98.9\%) and $92.5 \%(40.5 \%-99.8 \%)$ for patients with nonaggressive laBCC, and $77.0 \%(56.8 \%-97.3 \%)$ and $96.1 \%(22.6 \%-99.7 \%)$ for patients with $\mathrm{mBCC}$ receiving sonidegib 200 and $800 \mathrm{mg}$ QD, respectively.

\section{Subgroup analyses of GLI1 expression}

Marked reduction in GLII expression from baseline was overall consistent between subgroups of patients with laBCC and $\mathrm{mBCC}$ stratified by demographic (Figure 2) and baseline clinical characteristics (Figures 3 and 4). Median percent reduction for patients with aggressive laBCC ranged longitudinally (week 9 to EOT; lowest and highest value shown) $75.1 \%-98.9 \%$ and $90.6 \%-97.5 \%$ for those $<65$ years, and $64.4 \%-94.8 \%$ and $92.9 \%-98.9 \%$ for those $\geq 65$ years receiving sonidegib 200 and 800 mg QD, respectively. For patients with nonaggressive laBCC, median percent reduction ranged longitudinally $73.0 \%-96.6 \%$ and $62.6 \%-96.4 \%$ in patients younger than 65 years, and $48.1 \%-98.1 \%$ and $87.9 \%-98.9 \%$ in patients $\geq 65$ years receiving sonidegib 200 and $800 \mathrm{mg}$ $\mathrm{QD}$, respectively. Patients with $\mathrm{mBCC}$ achieved median percent reduction ranging longitudinally $91.7 \%-97.8 \%$ and $96.1 \%-99.3 \%$ for those younger than 65 years, and $56.8 \%-99.6 \%$ and $99.0 \%$ (data available for 1 patient for week 9 only) for patients $\geq 65$ years receiving sonidegib 200 and $800 \mathrm{mg}$ QD, respectively.

Patient subgroups stratified by BCC cytological subtype demonstrated relatively consistent reduction in GLI1 expression from baseline across subtypes (Table 1).

\section{Association between GLI1 levels and efficacy outcomes}

Substantial reductions in GLII levels from baseline were observed in patients with disease control (complete response [CR], partial response [PR], or stable disease [StDis]), with median percent reduction ranging $74.5 \%$ 


\begin{tabular}{|c|c|c|c|c|c|c|}
\hline & \multicolumn{3}{|c|}{$200 \mathrm{mg}$ QD } & \multicolumn{3}{|c|}{$800 \mathrm{mg}$ QD } \\
\hline & \multicolumn{2}{|c|}{ laBCC } & \multirow[t]{2}{*}{$\mathrm{mBCC}$} & \multicolumn{2}{|c|}{ laBCC } & \multirow[t]{2}{*}{$\mathrm{mBCC}$} \\
\hline & Aggressive & Nonaggressive & & Aggressive & Nonaggressive & \\
\hline Basosquamous & $n=0$ & $n=1$ & $n=2$ & $n=1$ & $n=0$ & $n=0$ \\
\hline Week 9 & - & $99.1(\mathrm{NE})$ & - & $98.3(\mathrm{NE})$ & - & - \\
\hline Week 17 & - & $85.2(\mathrm{NE})$ & - & 99.3 (NE) & - & - \\
\hline EOT & - & - & - & - & - & - \\
\hline Infiltrative & $n=21$ & $n=3$ & $n=3$ & $n=28$ & $n=6$ & $n=3$ \\
\hline Week 9 & $77.0(53.7-99.1)$ & $86.7(61.0-99.1)$ & $91.7(85.1-98.2)$ & $94.3(88.0-98.4)$ & $99.2(98.0-99.5)$ & $99.2(99.0-99.3)$ \\
\hline Week 17 & $76.5(30.7-92.3)$ & $97.6(93.0-99.1)$ & $97.8(96.4-99.1)$ & $85.8(58.5-98.9)$ & $89.7(80.7-98.8)$ & 99.9 (NE) \\
\hline EOT & $97.7(67.9-98.9)$ & - & $97.3(\mathrm{NE})$ & $96.9(35.8-99.7)$ & - & 99.7 (NE) \\
\hline Micronodular & $n=0$ & $n=0$ & $n=0$ & $n=2$ & $n=0$ & $n=0$ \\
\hline Week 9 & - & - & - & 99.7 (NE) & - & - \\
\hline Week 17 & - & - & - & $75.7(52.0-99.3)$ & - & - \\
\hline EOT & - & - & - & - & - & - \\
\hline Multifocal & $n=1$ & $n=0$ & $n=0$ & $n=0$ & $n=2$ & $n=0$ \\
\hline Week 9 & 63.7 (NE) & - & - & - & 99.1 (NE) & - \\
\hline Week 17 & $75.5(\mathrm{NE})$ & - & - & - & - & - \\
\hline EOT & - & - & - & - & - & - \\
\hline Nodular & $n=8$ & $n=14$ & $n=1$ & $n=9$ & $n=8$ & $n=1$ \\
\hline Week 9 & $87.4(18.8-98.2)$ & $83.4(62.6-95.2)$ & 98.5 (NA) & $87.8(5.0-99.8)$ & $98.5(76.5-99.4)$ & $94.2(\mathrm{NE})$ \\
\hline Week 17 & $93.0(34.9-99.9)$ & $98.1(76.0-99.5)$ & 99.6 (NA) & $97.0(62.4-99.9)$ & $30.2(93.2-99.3)$ & 95.9 (NE) \\
\hline EOT & - & $84.1(49.5-98.9)$ & - & $94.1(91.2-97.1)$ & $81.2(62.6-99.7)$ & $22.6(\mathrm{NE})$ \\
\hline Morpheaform & $n=5$ & $n=0$ & $n=1$ & $n=3$ & $n=2$ & $n=0$ \\
\hline Week 9 & $91.8(18.2-99.1)$ & - & - & $70.7(36.7-92.2)$ & 94.5 (91.4-97.6) & - \\
\hline Week 17 & $97.1(21.0-99.1)$ & - & - & $88.7(81.7-91.8)$ & $98.6(97.5-99.7)$ & - \\
\hline EOT & $93.4(90.8-96.0)$ & - & $56.8(\mathrm{NE})$ & 98.9 (NE) & - & - \\
\hline Superficial & $n=1$ & $n=7$ & $n=1$ & $n=2$ & $n=11$ & $n=0$ \\
\hline Week 9 & 99.5 (NE) & $91.5(73.0-98.3)$ & - & 91.8 (83.7-99.9) & $95.7(86.5-98.9)$ & - \\
\hline Week 17 & $60.5(\mathrm{NE})$ & $96.6(7.3-98.6)$ & - & $99.3(99.2-99.5)$ & $93.6(62.1-95.6)$ & - \\
\hline EOT & - & 33.1 (NE) & - & 99.9 (NE) & $92.5(40.5-98.9)$ & - \\
\hline Other & $n=0$ & $n=0$ & $n=0$ & $n=1$ & $n=1$ & $n=1$ \\
\hline Week 9 & - & - & - & - & $97.2(\mathrm{NE})$ & $99.6(\mathrm{NE})$ \\
\hline Week 17 & - & - & - & - & $95.6(\mathrm{NE})$ & $99.3(\mathrm{NE})$ \\
\hline EOT & - & - & - & - & - & 96.1 (NE) \\
\hline
\end{tabular}

All data presented as median, \% (95\% CI), unless otherwise noted. CI, confidence interval; EOT, end of treatment; GLI1, Glioma-associated oncogene homolog 1; laBCC, locally aggressive basal cell carcinoma; $\mathrm{mBCC}$, metastatic basal cell carcinoma; NE, not estimable due to 1 patient in group; QD, once daily.

$97.9 \%$ and $95.7 \%-98.0 \%$ at week 9 , and $90.8 \%-99.5 \%$ and $96.1 \%-97.0 \%$ at week 17 , for the 200 and $800 \mathrm{mg}$ groups, respectively (Supplementary Table 2). However, a significant association was not observed between strength of GLI1 repression and odds of tumor response (CR+PR), with hazard ratio (HR; $95 \% \mathrm{CI}, P$-value) for low vs high tumor inhibition of $1.4(0.5-3.8, P=0.4838)$ and 0.8 (0.3-2.0, $P=0.6627)$, for the 200 and $800 \mathrm{mg}$ groups, respectively (Supplementary Table 3).

Overall, no significant association was observed between extent of GLI1 inhibition and time to tumor response (TTR), with $\mathrm{HR}(95 \% \mathrm{CI}, P$-value) for low vs high expression of $0.9(0.4-1.9, P=0.4932)$ and 1.4
(0.7-2.8, $P=0.3148)$ for the 200 and $800 \mathrm{mg}$ groups, respectively (Supplementary Table 4).

\section{Association between GLI1 levels and time to onset of grade $\geq 2$ creatine kinase elevation}

There was no overall significant association between extent of GLII inhibition and time to onset of grade $\geq$ 2 creatine kinase (CK) elevation, with $\mathrm{HR}(95 \% \mathrm{CI}$, $P$-value) for low vs high expression of $0.6(0.2-2.5, P=$ $0.3348)$ and $1.2(0.5-2.6, P=0.3348)$ for the 200 and 800 mg groups, respectively (Supplementary Table 5). Among patients with greater GLI1 inhibition from baseline, those 
in the $800 \mathrm{mg}$ dose group had an increased risk of grade $\geq$ 2 CK elevation, with HR ( $95 \% \mathrm{CI}, P$-value) vs the $200 \mathrm{mg}$ dose of $2.3(0.8-6.2, P=0.0406)$.

\section{DISCUSSION}

Results from this secondary analysis suggest that sonidegib treatment led to substantial reductions in GLI1 levels from baseline across doses, BCC subtypes, examined time points, and demographic and baseline disease characteristics in patients with advanced BCC. Marked reductions in GLII levels from baseline were observed in patients who achieved disease control with sonidegib, consistent with Hedgehog pathway inhibition.

The Hedgehog pathway plays a key role in regulating cell proliferation and differentiation during development and is involved in the maintenance and repair of many adult tissues including the skin, hair, muscles, and nervous system [19]. Upon activation of the pathway, a signaling ligand of the Hedgehog family binds the transmembrane receptor PTCH1 [20]. This causes the G-protein coupled receptor SMO — sonidegib's target in the pathway - to dissociate from PTCH1 and migrate to the primary cilium, where it releases the cytoplasmic sequestration of the GLI family of transcription factors by Suppressor of Fused through a multistep signaling cascade [20]. Noncanonical pathways of GLI1 activation have also been reported, including by the Ras and p53 families of tumor suppressors [21]. Aberrant GLI1 activation promotes tumor growth, migration, and angiogenesis [21].

Despite the overall durable efficacy of sonidegib treatment observed in the BOLT study, a subset of patients develop resistance to HHIs that can be either primary or acquired after initial response to treatment [22]. Moreover, although GLI1 suppression is dose- and exposuredependent, a reduction of GLI1 expression did not always correlate with tumor response in the phase 1 efficacy and safety study for sonidegib, most likely due to limited sample size, indicating resistance may develop despite GLI1 inhibition [10]. The strong-but not completeinhibition of GLI1 expression in this biomarker analysis is consistent with the possibility that patients with low GLI1 inhibition are resistant to sonidegib. However, there was no significant correlation between sonidegib efficacy and the strength of GLII inhibition. This is possibly due to the study not being sufficiently powered to confirm this correlation. Additionally, inhibition of GLI1 in the different patient subgroups examined was uniformly strong, and none of the examined demographic and baseline clinical characteristics showed strong correlation with sonidegib resistance.

Animal and cell-line cancer models studied the impact of sonidegib on Hedgehog pathway activity. In human primary glioblastoma initiating cells, sonidegib reduces levels of GLI1, GLI2, PTCH1, and PTCH2 messenger ribonucleic acid (RNA) and protein, as well
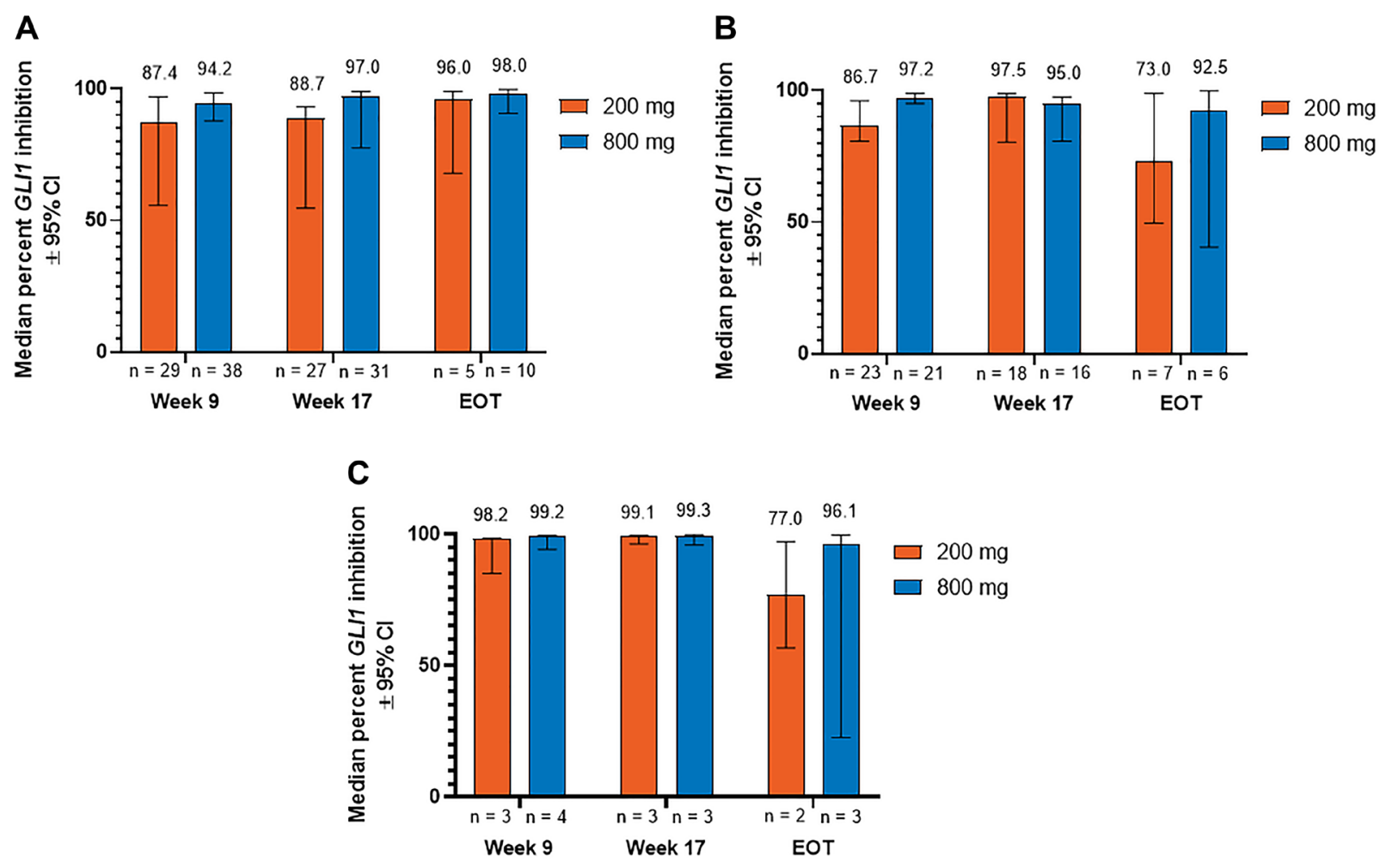

Figure 1: Percent inhibition of GLI1 expression relative to baseline in patients with $(\mathbf{A})$ aggressive laBCC, $(\mathbf{B})$ nonaggressive laBCC, and (C) mBCC. BCC, basal cell carcinoma; CI, confidence interval; EOT, end of treatment; GLI1, Glioma associated oncogene homolog 1; laBCC, locally advanced BCC; mBCC, metastatic BCC. 
as GLI1 and GLI2 translocation into the nucleus [23]. Epistasis testing using sonidegib in combination with direct GLI1 and GLI2 inhibition by RNA interference revealed the effect of sonidegib on Hedgehog pathway downstream targets, including upregulation of the cell death mediators, Fas, Death receptor (DR)4, and DR5, and downregulation of the cell proliferation mediators B-cell lymphoma 2 and Platelet-derived growth factor receptor A [23]. In human renal cell carcinoma lines, sonidegib
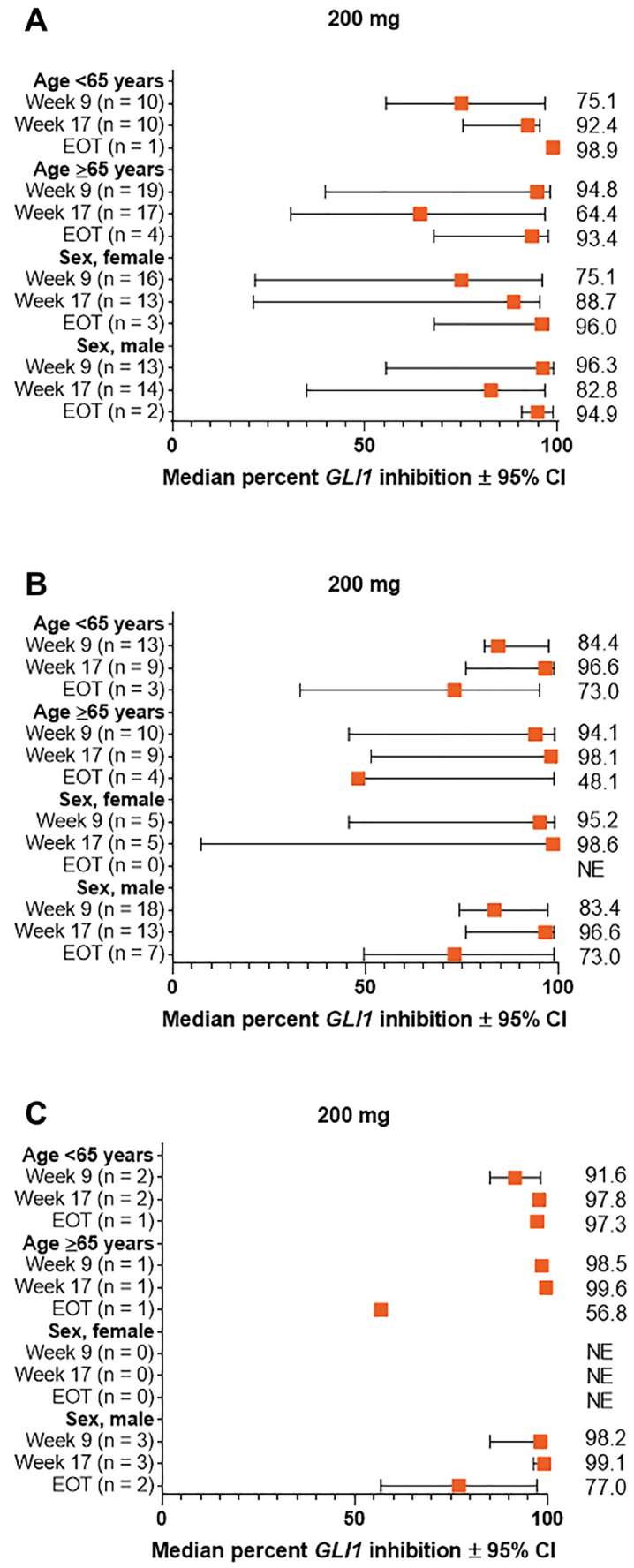

inhibited GLI1 and GLI2 and reduced cell proliferation in combination with everolimus or sunitinib, whereas direct inhibition of GLI1 and GLI2 in combination with everolimus or sunitinib had no impact on proliferation, suggesting that other targets downstream of SMO may play a role in tumor response [24].

This analysis found no significant association between the magnitude of GLII inhibition and time to onset of grade $\geq 2 \mathrm{CK}$ elevation-suggesting that
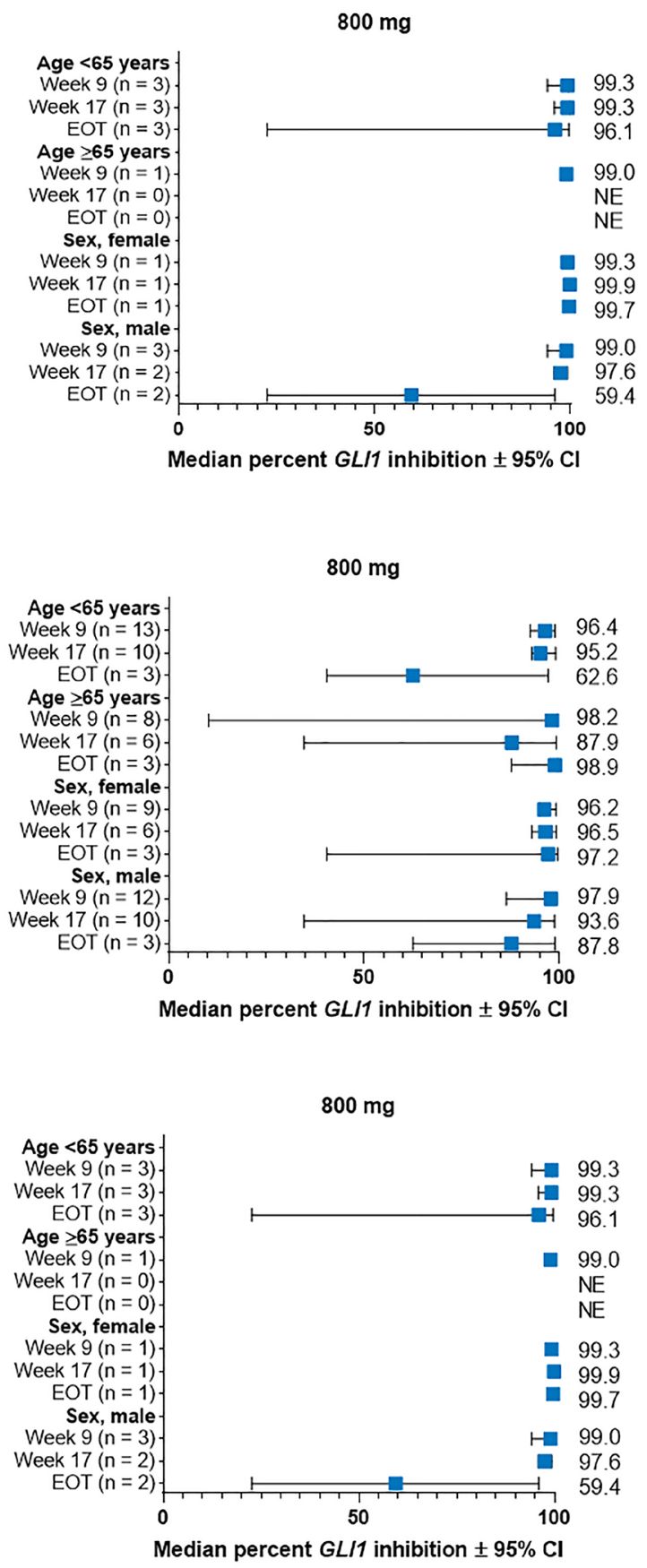

Figure 2: Percent change from baseline in GLI1 expression in subgroups by demographic characteristics for patients with (A) aggressive laBCC, (B) nonaggressive laBCC, and (C) mBCC. BCC, basal cell carcinoma; CI, confidence interval; EOT, end of treatment; GLI1, Glioma associated oncogene homolog 1; laBCC, locally advanced BCC; mBCC, metastatic BCC; NE, not estimable. 
CK elevation is not influenced by the extent of GLII inhibition. CK elevation is a common treatment-emergent AE observed in patients treated with Hedgehog inhibitors. While the exact mechanism responsible for muscle spasms and increased CK levels in patients receiving HHIs is not completely understood, muscle spasms are considered to

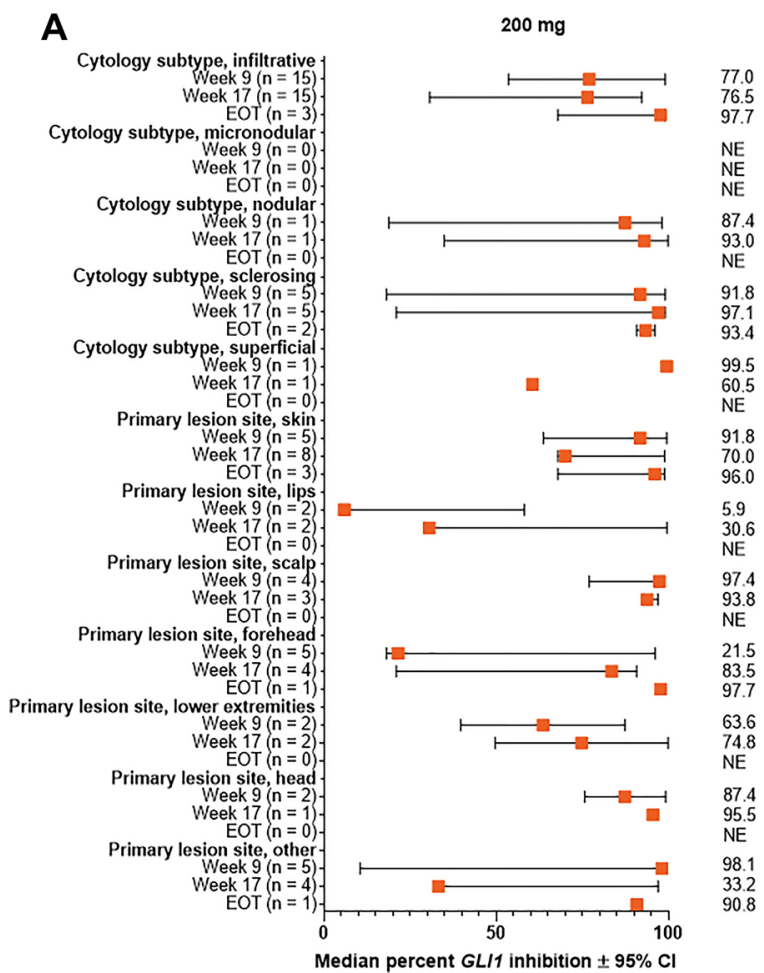

B

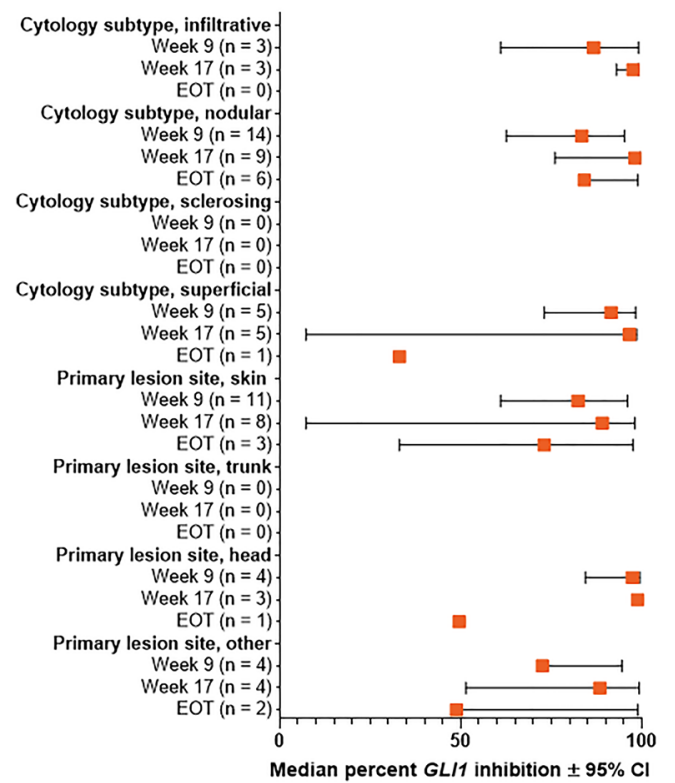

be linked with paradoxical activation of the SMO/calcium/ AMP-activated protein kinase axis, and the inhibition of $S M O$ signaling leads to an influx of calcium into muscle cells [25]. The pivotal clinical studies of vismodegib (Erivedge $^{\circledR}$, Genentech, South San Francisco, CA), an $\mathrm{HHI}$ indicated for the treatment of advanced BCC, did not
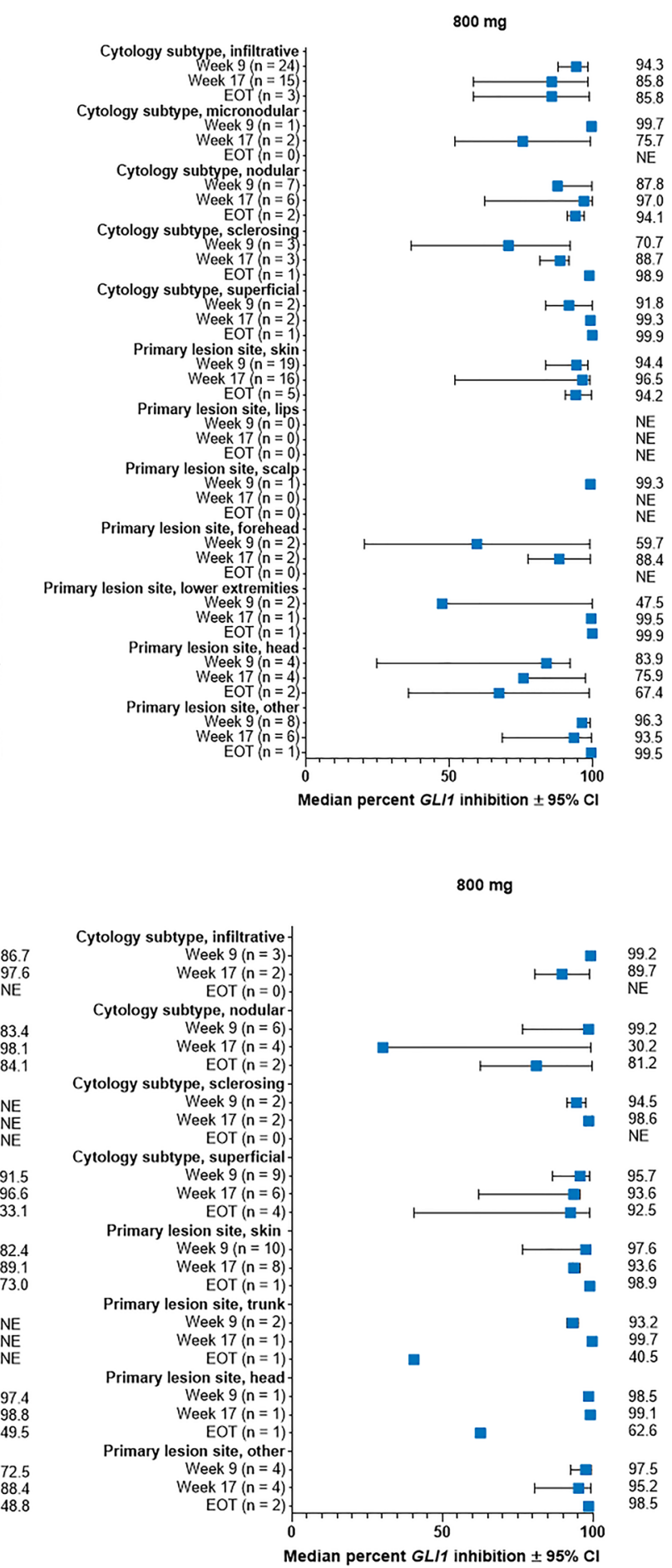

Figure 3: Percent change from baseline in GLI1 expression in subgroups by lesion cytology and site for patients with (A) aggressive laBCC, (B) nonaggressive laBCC. Results are shown for subgroups with $>1$ patient in either dose group. All subgroups for patients with $\mathrm{mBCC}$ had $\leq 1$ patient. BCC, basal cell carcinoma; CI, confidence interval; EOT, end of treatment; GLI1, Glioma associated oncogene homolog 1; laBCC, locally advanced $\mathrm{BCC}$; $\mathrm{mBCC}$, metastatic $\mathrm{BCC}$; NE, not estimable. 

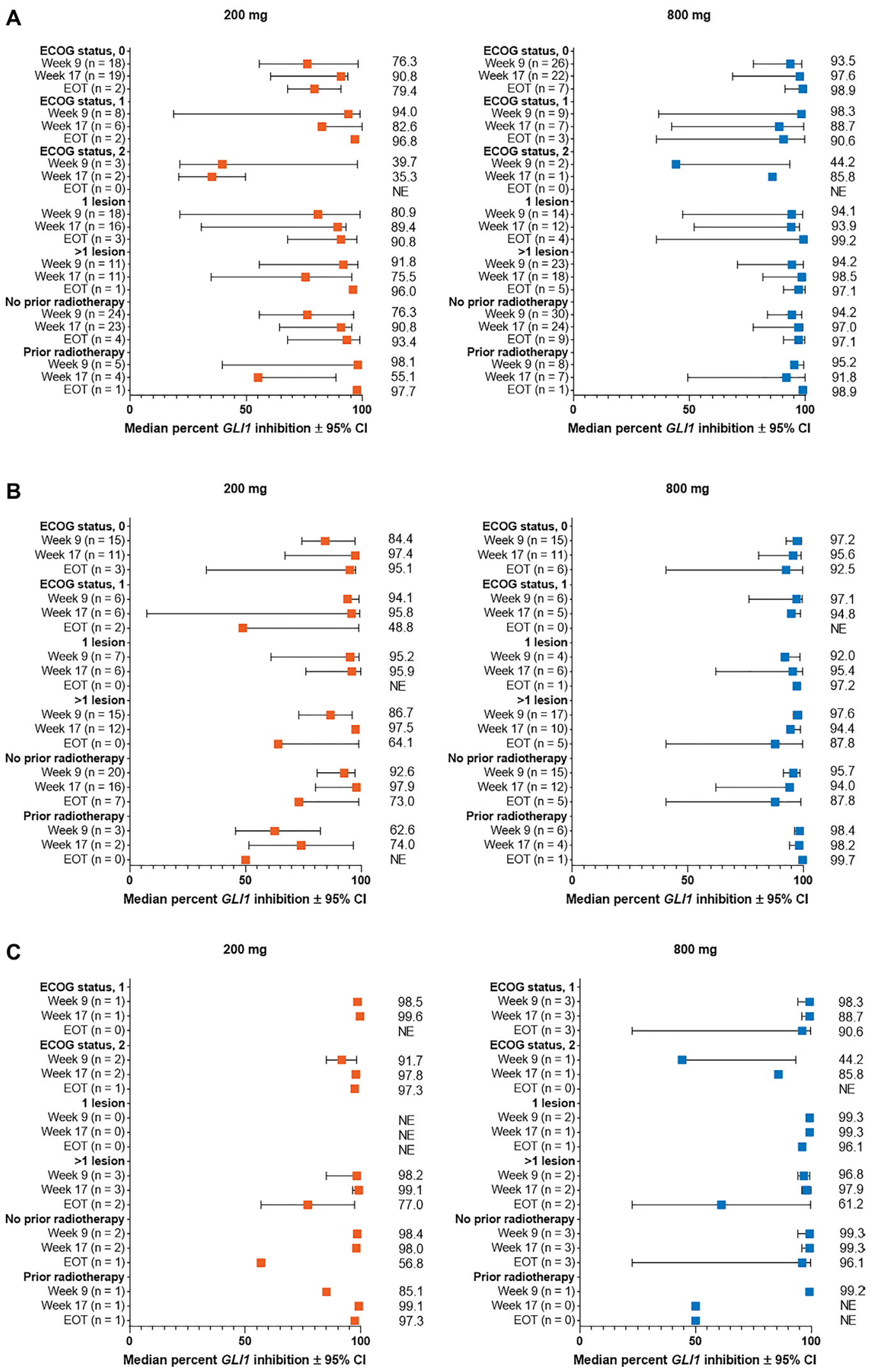

Figure 4: Percent change from baseline in GLII expression in subgroups by Eastern Cooperative Oncology Group status, number of lesions, and prior radiotherapy for patients with (A) aggressive laBCC, (B) nonaggressive laBCC, and (C) $\mathrm{mBCC}$. BCC, basal cell carcinoma; CI, confidence interval; EOT, end of treatment; GLI1, Glioma associated oncogene homolog 1; laBCC, locally advanced BCC; $\mathrm{mBCC}$, metastatic BCC; NE, not estimable. 
include CK monitoring; however, muscle spasms were reported in $71.2 \%$ of patients [26]. All currently approved HHIs have the same mechanism of action and similar safety profiles; it is thought that $\mathrm{CK}$ elevation and muscle spasms are HHI class-effect AEs.

Limitations of the current study include the lack of statistical power to assess specific biomarker-related hypotheses. All biomarker analysis should be considered exploratory and hypothesis-generating, and all $P$-values were nominal or were adjusted for multiplicity only at the biomarker level within a specific model or analysis. GLI1 was the only examined biomarker, and data on the expression of other prominent members of the pathway were not collected. Additionally, GLII expression as related to reduction in tumor mass was not directly evaluated in this analysis. Subsequently, decreases in tumor size may have contributed to reductions in GLII levels measured following treatment.

In summary, the reduction of GLI1 expression is consistent with potent inhibition of the Hedgehog pathway by sonidegib in patients with laBCC and mBCC. These results support further clinical studies on the impact of sonidegib on Hedgehog pathway biomarkers.

\section{MATERIALS AND METHODS}

\section{BOLT study design}

This randomized, double-blind, adaptive phase 2 multicenter study adhered to the ethical principles of the Declaration of Helsinki and received approval for its protocol and all amendments from an Independent Ethics Committee or Institutional Review Board at each study site. Written informed consent was obtained from all patients before any study-specific procedures.

Study design is described in detail elsewhere and is briefly summarized here and in Supplementary Figure 2. The study enrolled men and women age $\geq 18$ years with a histologically confirmed diagnosis of $\mathrm{mBCC}$ or laBCC (not amenable to radiation therapy, curative surgery, or other local therapies) and a World Health Organization (WHO) performance status $\leq 2$. Patients were randomized 1:2 to receive sonidegib 200 or $800 \mathrm{mg}$ QD until disease progression, unacceptable toxicity, withdrawal of consent, study termination, or death.

\section{BOLT efficacy assessments}

Tumor response was evaluated with Response Evaluation Criteria in Solid Tumors (RECIST) version 1.1 for patients with $\mathrm{mBCC}$. For laBCC, the standard RECIST 1.1 criteria are inadequate, since posttreatment morphological changes such as ulceration, cyst formation, and scarring may confound tumor response evaluation. A modified (m)RECIST protocol was developed to assess tumor response in laBCC, integrating central histological review, one-dimensional localized soft-tissue magnetic resonance imaging (MRI) along the lesion's longest diameter per RECIST 1.1, and bidimensional color photography measurements per WHO guidelines.

The primary efficacy endpoint was ORR per central review. Secondary efficacy assessments included TTR and best overall response (either CR, PR, StDis, progressive disease, or unknown). Best overall response was assessed by central review according to mRECIST in patients with laBCC and RECIST 1.1 in patients with mBCC. mRECIST criteria includes a combination of MRI scans, color photography, and baseline and follow-up histopathology data for patients to assess tumor response.

\section{BOLT safety assessments}

Safety assessments included AEs monitored throughout the study, coded using the medical Dictionary for Regulatory Activities version 19.0, and assessed for toxicity using the National Cancer Institute Common Terminology Criteria for Adverse Events version 4.03. CK levels were assessed prior to starting treatment or within 72 hours of the first dose, then weekly during the first 2 months, and every 4 weeks thereafter while on study treatment.

\section{Biomarker assessments}

Biopsies were collected from accessible lesions at Screening, weeks 9 and 17 predose, and within 21 days after the last dose of study drug. For patients with multiple lesions, no specific lesion was designated for biopsy, and any lesion could be used. Presence of tumor tissue in biopsy samples was histologically confirmed prior to biomarker analysis.

GLII expression at Screening was used as baseline measurement. Gene expression at all examined time points was assessed using reverse transcriptase polymerase chain reaction, in terms of the number of reaction cycles needed to reach the threshold amount of product. Expression of GLII at each time point was normalized to the housekeeping gene ubiquitin $\mathrm{C}$, and fold and percent change from baseline of normalized GLII expression were computed.

Percent change from baseline in GLI1 expression was stratified by type of BCC (aggressive and nonaggressive laBCC and $\mathrm{mBCC}$ ), age, sex, number of lesions at baseline, cytology subtype, primary site of cancer, prior radiotherapy, and Eastern Cooperative Oncology Group performance status. Association between GLII expression and select efficacy and safety assessments was evaluated, including best overall response, TTR, and time to onset of grade $\geq 2$ CK elevation.

\section{Statistical analyses}

The ITT population included all randomized patients. The subset of the ITT population with valid 
biomarker samples comprised the biomarker population used for all biomarker analyses. Data collected up to 6 months after the last patient randomization date were included in the analysis. All statistical evaluations were exploratory since the study was not powered to assess specific hypotheses regarding change in GLII expression. Since inhibition of the Hedgehog pathway with sonidegib should result in GLII inhibition, postbaseline records with $>100 \%$ change in GLII levels from baseline were considered outliers and were excluded from analyses and models.

Visual assessments of strip plots determined the relationship between baseline GLI1 levels or changes from baseline in GLI1 levels and clinical efficacy outcomes. Percent change in GLII levels was summarized using descriptive statistics (mean, 95\% CI, median, 95\% distribution-free CI, SD, quartiles, and range). Longitudinal analyses of GLII expression were performed using a linear mixed model, including fold change in GLII expression from baseline as a response variable and visit, treatment group, and visit-by-treatment interaction as covariates. Median percent change from baseline and 95\% CI for each dose group and time point were computed based on model-based least squares mean fold change estimates.

Cox proportional hazards models determined associations between baseline GLII levels or changes from baseline in GLI1 levels, and TTR and time to onset of grade $\geq 2$ CK elevation. Kaplan-Meier curves and logrank test-based $P$-values for the difference in time-toonset curves were produced for groups defined by dose level and categorized GLII levels. Normalized baseline GLI1 levels were categorized as low or high based on the median (both doses combined). Percent change in GLII from baseline at week 9 or 17 was categorized as low (greater inhibition) or high (lesser inhibition) based on the third quartile (both doses combined).

\section{Abbreviations}

AE: adverse event; BCC: basal cell carcinoma; BOLT: Basal cell carcinoma Outcomes with LDE225 (sonidegib) Treatment; CI: confidence interval; CK: creatine kinase; CR: complete response; DR: death receptor; EOT: end of treatment; GLI1: Glioma-associated oncogene homolog 1; HHI: Hedgehog pathway inhibitor; HR: hazard ratio; ITT: intent-to-treat; laBCC: locally advanced BCC; mBCC: metastatic BCC; mRECIST: modified RECIST; MRI: magnetic resonance imaging; ORR: objective response rate; PR: partial response; PTCH1: Patched 1; QD: once daily; RECIST: Response Evaluation Criteria in Solid Tumors; RNA: ribonucleic acid; SMO: Smoothened; SD: standard deviation; StDis: stable disease; TTR: time to tumor response; WHO: World Health Organization.

\section{Author contributions}

Reinhard Dummer, Ralf Gutzmer, Nicholas Squittieri and John Lear critically reviewed and edited the manuscript. Li Liu did the biostatistics of data and critically reviewed and edited the manuscript.

\section{ACKNOWLEDGMENTS}

This study was sponsored and funded by Novartis and Sun Pharmaceutical Industries, Inc. Writing and editorial support for manuscript preparation were provided by Ginny Feltzin, PhD, and Zehra Gundogan, VMD, of AlphaBioCom, LLC, and funded by Sun Pharmaceutical Industries, Inc. All authors met the International Council of Medical Journal Editors criteria and received neither honoraria nor payment for authorship.

\section{CONFLICTS OF INTEREST}

R. Dummer has participated on advisory boards and consulted for Amgen; Bristol-Myers Squibb; CatalYm; Merck Sharp \& Dohme; Novartis Pharmaceutical Corporation; Pierre-Fabre; Roche; Sanofi; Second Genome; Sun Pharmaceutical Industries, Inc.; and Takeda. L. Liu and N. Squittieri are employees of Sun Pharmaceutical Industries, Inc. R. Gutzmer serves as consultant to Almirall; Amgen; Bristol-Myers Squibb; Merck Serono; Merck Sharp \& Dohme; Novartis; Pfizer; Pierre-Fabre; Roche; Sanofi Genzyme; Sun Pharmaceutical Industries, Inc.; and 4SC; has received travel grants and honoraria for lectures from Almirall; Amgen; Bristol-Myers Squibb; Merck-Serono; Merck Sharp \& Dohme; Novartis; Pierre-Fabre; Roche; Sun Pharmaceutical Industries, Inc.; and received research funding from Amgen, Johnson \& Johnson, Merck-Serono, Novartis. J. Lear receives personal fees from Novartis and Sun Pharmaceutical Industries, Inc.

\section{FUNDING}

This work was supported by Sun Pharmaceutical Industries, Inc.

\section{REFERENCES}

1. Asgari MM, Moffet HH, Ray GT, Quesenberry CP. Trends in Basal Cell Carcinoma Incidence and Identification of High-Risk Subgroups, 1998-2012. JAMA Dermatol. 2015; 151:976-981. https://doi.org/10.1001/ jamadermatol.2015.1188. [PubMed]

2. Lucas RM, McMichael AJ, Armstrong BK, Smith WT. Estimating the global disease burden due to ultraviolet radiation exposure. Int J Epidemiol. 2008; 37:654-667. https://doi.org/10.1093/ije/dyn017. [PubMed] 
3. Xiang F, Lucas R, Hales $\mathrm{S}$, Neale R. Incidence of nonmelanoma skin cancer in relation to ambient UV radiation in white populations, 1978-2012: empirical relationships. JAMA Dermatol. 2014; 150:1063-1071. https://doi.org/10.1001/jamadermatol.2014.762. [PubMed]

4. Work G, Invited R, Kim JYS, Kozlow JH, Mittal B, Moyer J, Olencki T, Rodgers P. Guidelines of care for the management of basal cell carcinoma. J Am Acad Dermatol. 2018; 78:540-559. https://doi.org/10.1016/j. jaad.2017.10.006. [PubMed]

5. Dreier J, Cheng PF, Bogdan Alleman I, Gugger A, Hafner J, Tschopp A, Goldinger SM, Levesque MP, Dummer R. Basal cell carcinomas in a tertiary referral centre: a systematic analysis. Br J Dermatol. 2014; 171:1066-1072. https://doi. org/10.1111/bjd.13217. [PubMed]

6. Epstein EH. Basal cell carcinomas: attack of the hedgehog. Nat Rev Cancer. 2008; 8:743-754. https://doi.org/10.1038/ nrc2503. [PubMed]

7. Gailani MR, Ståhle-Bäckdahl M, Leffell DJ, Glynn M, Zaphiropoulos PG, Pressman C, Undén AB, Dean M, Brash DE, Bale AE, Toftgård R. The role of the human homologue of Drosophila patched in sporadic basal cell carcinomas. Nat Genet. 1996; 14:78-81. https://doi.org/10.1038/ng099678. [PubMed]

8. Xie J, Murone M, Luoh SM, Ryan A, Gu Q, Zhang C, Bonifas JM, Lam CW, Hynes M, Goddard A, Rosenthal A, Epstein EH Jr, de Sauvage FJ. Activating Smoothened mutations in sporadic basal-cell carcinoma. Nature. 1998; 391:90-92. https://doi.org/10.1038/34201. [PubMed]

9. Scales SJ, de Sauvage FJ. Mechanisms of Hedgehog pathway activation in cancer and implications for therapy. Trends Pharmacol Sci. 2009; 30:303-312. https://doi. org/10.1016/j.tips.2009.03.007. [PubMed]

10. Rodon J, Tawbi HA, Thomas AL, Stoller RG, Turtschi CP, Baselga J, Sarantopoulos J, Mahalingam D, Shou Y, Moles MA, Yang L, Granvil C, Hurh E, et al. A phase I, multicenter, open-label, first-in-human, dose-escalation study of the oral smoothened inhibitor Sonidegib (LDE225) in patients with advanced solid tumors. Clin Cancer Res. 2014; 20:1900-1909. https://doi.org/10.1158/1078-0432. CCR-13-1710. [PubMed]

11. Lu T, Wang B, Gao Y, Dresser M, Graham RA, Jin JY. Semi-mechanism-based population pharmacokinetic modeling of the hedgehog pathway inhibitor vismodegib. CPT Pharmacometrics Syst Pharmacol. 2015; 4:680-689. https://doi.org/10.1002/psp4.12039. [PubMed]

12. Lorusso PM, Jimeno A, Dy G, Adjei A, Berlin J, Leichman L, Low JA, Colburn D, Chang I, Cheeti S, Jin JY, Graham RA. Pharmacokinetic dose-scheduling study of hedgehog pathway inhibitor vismodegib (GDC-0449) in patients with locally advanced or metastatic solid tumors. Clin Cancer Res. 2011; 17:5774-5782. https://doi.org/10.1158/10780432.CCR-11-0972. [PubMed]

13. LoRusso PM, Rudin CM, Reddy JC, Tibes R, Weiss GJ, Borad MJ, Hann CL, Brahmer JR, Chang I, Darbonne WC,
Graham RA, Zerivitz KL, Low JA, et al. Phase I trial of hedgehog pathway inhibitor vismodegib (GDC-0449) in patients with refractory, locally advanced or metastatic solid tumors. Clin Cancer Res. 2011; 17:2502-2511. https://doi. org/10.1158/1078-0432.CCR-10-2745. [PubMed]

14. Graham RA, Lum BL, Cheeti S, Jin JY, Jorga K, Von Hoff DD, Rudin CM, Reddy JC, Low JA, Lorusso PM. Pharmacokinetics of hedgehog pathway inhibitor vismodegib (GDC-0449) in patients with locally advanced or metastatic solid tumors: the role of alpha-1-acid glycoprotein binding. Clin Cancer Res. 2011; 17:25122520. https://doi.org/10.1158/1078-0432.CCR-10-2736. [PubMed]

15. Dummer R, Guminksi A, Gutzmer R, Lear JT, Lewis KD, Chang ALS, Combemale P, Dirix L, Kaatz M, Kudchadkar R, Loquai C, Plummer R, Schulze HJ, et al. Long-term efficacy and safety of sonidegib in patients with advanced basal cell carcinoma: 42-month analysis of the phase 2 randomised, double-blind BOLT study. Br J Dermatol. 2020; 182:1369-1378. https://doi.org/10.1111/bjd.18552. [PubMed]

16. Dummer R, Guminski A, Gutzmer R, Dirix L, Lewis KD, Combemale P, Herd RM, Kaatz M, Loquai C, Stratigos AJ, Schulze HJ, Plummer R, Gogov S, et al. The 12-month analysis from Basal Cell Carcinoma Outcomes with LDE225 Treatment (BOLT): A phase II, randomized, double-blind study of sonidegib in patients with advanced basal cell carcinoma. J Am Acad Dermatol. 2016; 75:11325.e5. https://doi.org/10.1016/j.jaad.2016.02.1226. [PubMed]

17. Lear JT, Migden MR, Lewis KD, Chang ALS, Guminski A, Gutzmer R, Dirix L, Combemale P, Stratigos A, Plummer R, Castro H, Yi T, Mone M, et al. Long-term efficacy and safety of sonidegib in patients with locally advanced and metastatic basal cell carcinoma: 30-month analysis of the randomized phase 2 BOLT study. J Eur Acad Dermatol Venereol. 2018; 32:372-381. https://doi.org/10.1111/jdv.14542. [PubMed]

18. Migden MR, Guminski A, Gutzmer R, Dirix L, Lewis KD, Combemale P, Herd RM, Kudchadkar R, Trefzer U, Gogov S, Pallaud C, Yi T, Mone M, et al. Treatment with two different doses of sonidegib in patients with locally advanced or metastatic basal cell carcinoma (BOLT): a multicentre, randomised, double-blind phase 2 trial. Lancet Oncol. 2015; 16:716-728. https://doi.org/10.1016/S14702045(15)70100-2. [PubMed]

19. Petrova R, Joyner AL. Roles for Hedgehog signaling in adult organ homeostasis and repair. Development. 2014; 141:34453457. https://doi.org/10.1242/dev.083691. [PubMed]

20. Athar M, Li C, Kim AL, Spiegelman VS, Bickers DR. Sonic hedgehog signaling in Basal cell nevus syndrome. Cancer Res. 2014; 74:4967-4975. https://doi.org/10.1158/00085472.CAN-14-1666. [PubMed]

21. Carpenter RL, Lo HW. Hedgehog pathway and GLI1 isoforms in human cancer. Discov Med. 2012; 13:105-113. [PubMed] 
22. Migden MR, Chang ALS, Dirix L, Stratigos AJ, Lear JT. Emerging trends in the treatment of advanced basal cell carcinoma. Cancer Treat Rev. 2018; 64:1-10. https://doi. org/10.1016/j.ctrv.2017.12.009. [PubMed]

23. Fu J, Rodova M, Nanta R, Meeker D, Van Veldhuizen PJ, Srivastava RK, Shankar S. NPV-LDE-225 (Erismodegib) inhibits epithelial mesenchymal transition and self-renewal of glioblastoma initiating cells by regulating miR-21, miR128, and miR-200. Neuro Oncol. 2013; 15:691-706. https:// doi.org/10.1093/neuonc/not011. [PubMed]

24. D'Amato C, Rosa R, Marciano R, D'Amato V, Formisano L, Nappi L, Raimondo L, Di Mauro C, Servetto A, Fulciniti F, Cipolletta A, Bianco C, Ciardiello F, et al. Inhibition of Hedgehog signalling by NVP-LDE225 (Erismodegib) interferes with growth and invasion of human renal cell carcinoma cells. Br J Cancer. 2014; 111:1168-1179. https:// doi.org/10.1038/bjc.2014.421. [PubMed]

25. Dinehart MS, McMurray S, Dinehart SM, Lebwohl M. L-Carnitine reduces muscle cramps in patients taking vismodegib. SKIN The Journal of Cutaneous Medicine. 2018; 2:90-95.

26. Sekulic A, Migden MR, Basset-Seguin N, Garbe C, Gesierich A, Lao CD, Miller C, Mortier L, Murrell DF, Hamid O, Quevedo JF, Hou J, McKenna E, et al. Longterm safety and efficacy of vismodegib in patients with advanced basal cell carcinoma: final update of the pivotal ERIVANCE BCC study. BMC Cancer. 2017; 17:332. https://doi.org/10.1186/s12885-017-3286-5. [PubMed] 